\title{
Die Vertreibung als Zäsur im religiös-kulturellen Leben der ungarndeutschen Gemeinde Budaörs/Wudersch?
}

\author{
The expulsion as historical turning point in the religious and cultural \\ life of the German-Hungarian village Budaörs/Wudersch?
}

\begin{abstract}
The expulsion of the German minority in Hungary at the end of World War II started on the 19th of January 1946 in the small village Budaörs/Wudersch close to the capital Budapest. The village has become well-known in the interwar period for its flower carpets prepared for the feast Corpus Christi, made by its Germanspeaking population until over $90 \%$ of the inhabitants were forced to leave the country for the American occupation zone of Germany, a moment that has been long established as the historical turning point in the history and culture of the German minority in Hungary. The expulsion thus divides the tradition of making flower carpets for Corpus Christi into two eras. Previous research has often struggled with connecting these two eras with each other, when analyzing the development of the feast. The main goal of the research paper is to describe the situation of the Catholic Church in Hungary in the times of transition to Socialism, both on national and local level and to deconstruct the idea of the year 1946 being the one and only possible turning point when considering the changes in the tradition. A newly found source in the Esztergom Primatial Archives, an album with photos taken of the flower carpet in 1948, a present made for Cardinal Mindszenty, shows that the route of the procession has stayed the same, although changes in the number of observants and the lack of women wearing the traditional costume of Budaörs can be observed. These findings demonstrate a continuity of tradition and village life, straddling the supposed divide, and hence suggest a re-interpretation of the feast's significance as demonstration of the catholic inhabitants' resistance to the slowly establishing soviet system.
\end{abstract}

Keywords: German minority, religion studies, historical turning points, historical interpretation, local history

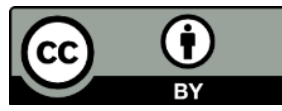




\section{Einleitung}

Der zu Fronleichnam gelegte Blumenteppich in der ungarndeutschen Gemeinde Budaörs/Wudersch, ${ }^{1}$ der „Perle des Ofner Berglandes“ ${ }^{\text {, }}$, ist dem Fach „Volkskunde“ und allgemein der Forschung längst nicht unbekannt: Elmar von Schwartz beschrieb 1930 in der Zeitscbrift für Volkskunde erstmals wissenschaftlich die Fronleichnamstraditionen im Ofner Bergland. In seinem Beitrag setzte sich Schwartz mit der Herkunft der Tradition auseinander und stellte die Festgestaltung in der Region, darunter auch in Budaörs, dar. ${ }^{3}$ Eugen von Bonomi, Schüler von Schwartz und des Nationalitätenpolitikers Jakob Bleyer, promovierte zum Thema religiöses Brauchtum in Budaörs. ${ }^{4}$ In seiner 1933 veröffentlichten Promotionsschrift Das Kirchenjahr in Spruch und Brauch der deutschen Gemeinde Budaörs legte Bonomi eine umfassende Analyse der dortigen Fronleichnamstraditionen vor. ${ }^{5}$ Mit der von den Heimatvertriebenen in die spätere Bundesrepublik translozierten Tradition des Blumenteppichlegens und ihrer Bedeutung für die kollektive Identität der Budaörser Vertriebenen beschäftigte sich Hans-Werner Retterath, wodurch die Aufarbeitung des Themas auch international Resonanz fand. ${ }^{6}$ Mehrere Arbeiten, die am besten unter dem Begriff heimatliche Literatur zusammengefasst werden können, befassen sich mit dem Fronleichnamsfest in Budaörs in seiner alten Form, mit dem Hinweis, dass es sich dabei um eine mittlerweile 300 Jahre „alten“ Tradition, ein mitgebrachtes Erbe der Siedler und Siedlerinnen aus ihrer „Urheimat" handelt.7 Beschreibungen des Festes in der heutigen Form beziehen sich auf die Vertreibung als eine Zäsur, die zu einer Verkürzung des Prozessionsweges führte, welcher nun nur mehr um die Kirche herum führen durfte. 8 Obwohl das Fest sich in seiner heutigen Form von den durch Bonomi und Schwartz beschriebenen Feierlichkeiten maßgebend unterscheidet, kam es bisher nicht zu einem umfassenden Vergleich der damaligen und gegenwärtigen Festgestaltung mit wissenschaftlichem Anspruch und unter Mitberück-

\footnotetext{
Korrekturleser: Karl Katschthaler

Riedl 1965.

3 Schwartz 1930.

4 Im Internationalen Germanistenlexikon ist Schwartz als Doktorvater angegeben, Bonomi promovierte aber bei Bleyer. Nach der Unstimmigkeit zwischen Schwartz und Bleyer sprach er sich für letzteren aus, was zu einer Auseinandersetzung mit Schwartz führte. Vgl. Szabó 2003: 232; siehe auch: Bonomi 1964: 274.

5 Bonomi 1933.

6 Retterath 2011.

Siehe: Kovácsné-Kovács 1999: 82, 87-88.

8 Siehe: Verebélyi 1998; vgl. Filipszky-Grósz 2009: 141.
} 
sichtigung der sozialen und politischen Entwicklungen des 20. Jahrhunderts. ${ }^{9}$ Mit der Vertreibung des Großteils der Brauchträger und Brauchträgerinnen änderte sich die Gestaltung des Fronleichnamsfestes gravierend. Wie und wann genau sich diese Veränderungen vollzogen, welche Schritte die Anpassung an die neuen politischen Gegebenheiten erforderte, wie der Verlust der alten Sozialstruktur der Gemeinde von der Dorfgemeinschaft aufgearbeitet wurde, wurden bisher nicht erforscht. ${ }^{10}$ Diese Lücken kann die vorliegende Arbeit nicht füllen. Ihr Ziel besteht vielmehr darin, „Bruchpunkte"11 auf lokaler Ebene darzustellen, und diese in Bezug auf die Fronleichnamstraditionen in Budaörs zu deuten. Dabei soll, mit dem Ziel, die Hypothese der Vertreibung als Zäsur in der Lokalgeschichte des Dorfes und ihre Gültigkeit auf die Gestaltung des Fronleichnamsfestes zu bestätigen oder zu entkräften, auf Entwicklungen des Festes in den Jahren 1944-1946, bzw. 1948 eingegangen werden. Die Vertreibung, das „Schlüsseljahr“"12 1946, als einzig mögliche Zäsur in der lokalen Festgestaltung soll somit dekonstruiert werden. Dies geschieht aufgrund der Analyse der einschlägigen Fachliteratur sowie der heimatlichen Literatur und Archivquellen, die zur breiten Etablierung dieser Zäsur beitrugen. Als „Gegenarchiv"13 zu den historischen Archivquellen soll ein Album im Erz̨bischöflichen Archiv in Esztergom (Gran), das József Kardinal Mindszenty 1948 aus Budaörs zum Geschenk gemacht wurde, herangezogen werden. ${ }^{14}$ Obwohl diese Quelle als Kolorit der Zeit unmittelbar nach der Vertreibung gilt, fand sie bisher keinen Eingang in die Forschung. Im vorliegenden Aufsatz wird dieses Material eingehend vorgestellt und ausgewertet. Dabei wird auch das Genre Album mit seinen wesentlichen Merkmalen thematisiert. Davor soll auf die Rolle der katolischen Kirche in der ungarischen Gesellschaft von 1945-1949 sowie auf ihre lokalen Entwicklungen in Budaörs eingegangen werden.

\footnotetext{
9 Anm. der Verfasserin: Im Fall von Budakesæi/Wudigeß, einem Nachbardorf von Budaörs, sind die Arbeiten von János Bednárik als solche zu nennen, die für künftige Arbeiten über Budaörs richtungsweisend und von essentieller Bedeutung sind. Besonders relevant zum Forschungsgegenstand ist: Bednárik 2014

10 In diesem Zusammenhang fokussierte die Forschung auf die Integration der Vertriebenen in der ,neuen Heimat“.

11 Marchut 2014.

12 Graf 2012: o.S.

13 Kramer-Pelz 2013: 16.

14 Obwohl Heimatbücher und Heimatzeitschriften oft als Quellen für diverse Forschungen herangezogen werden, wird auf ihre Analyse in der vorliegenden Arbeit verzichtet. Zum Thema Heimatbuch als Quelle siehe Marinka 2012, Marinka 2018. Zur Problematik der Heimatliteratur als Untersuchungsgegenstand oder als Quelle vgl. die Beiträge in Beer 2010.
} 


\section{Zum Forschungsstand}

„Zeit und Zeitvorstellungen sind wandelbar und daher jenseits der oftmals metaphorischen Verwendung des Zeitbegriffs ein wichtiger Gegenstand der Geschichtswissenschaft. "15 - formuliert Rüdiger Graf in einem Artikel, in dem er sich mit den Begriffen Zeit und Zeitkonzeptionen auseinandersetzt. Die Aussage von Graf gilt auch für die Erforschung der Deutschen in Ungarn: In der wissenschaftlichen Auseinandersetzung mit ihrer Geschichte setzte sich, auch wenn unausgesprochen, eine Teilung des Forschungsgegenstandes in die Zeit vor und nach der Vertreibung durch. Die Vertreibung, die am 19. Januar 1946 mit der sukzessiven Aussiedlung der Bevölkerung von Budaörs begann, etablierte sich als markanter Wendepunkt, als Zäsur in der Historiografie. Wie aber Martin Sabrow anmerkt, sind Zäsuren perspektivengebunden, daher auch subjektiv, sektoral und nicht umfassend. ${ }^{16}$ Aus diesem Grund setzte sich die Vertreibung als Zäsur nicht in allen Bereichen des Lebens und nicht gleichzeitig durch, deswegen kann sie nicht als allgemeingültige Zäsur betrachtet werden. ${ }^{17}$ Auch nach Gerhard Seewann ist „,[d]ie Geschichte des Ungarndeutschtums von 1945 bis zur Gegenwart" von mehreren Zäsuren geprägt, als solche definiert er die Jahre 1948 als Ende der Vertreibung und das Jahr 1949, in dem die erste sozialistische Verfassung in Ungarn in Kraft trat. ${ }^{18}$

Es muss darauf hingewiesen werden, dass sich der Umgang mit dem Thema in der Forschungspraxis in den „Ankunftsländern“ und in den Vertreibungsgebieten unterscheidet. Wie auch János Bednárik in einem Artikel darlegt, blühte in der zweiten Hälfte des 20. Jahrhunderts in der Bundesrepublik eine transdisziplinäre Heimatvertriebenenforschung auf, ${ }^{19}$ die auch in der Vergangenheitsbewältigung eine maßgebende Rolle spielte. Heimatvertriebene gerieten zugleich „mit dem Verlassen des Landes auch aus dem

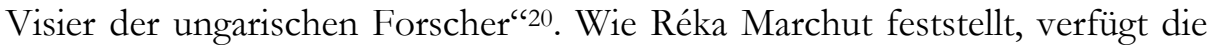
Vertreibung als Themenkreis in der Bundesrepublik auch über eine Relevanz, wenn zwischen den diversen Gruppen der Vertriebenen nicht nach Herkunftsland unterscheidet wird. ${ }^{21}$ Sie alle, d.h. alle Heimatvertriebenen bilden den Gegenstand der Heimatvertriebenenforschung, unabhängig von Her-

15 Graf 2012: o.S.

16 Sabrow 2014: o.S.

17 Sabrow 2014: o.S.

18 Seewann 1989: 97.

19 Bednárik 2017: 211-212.

20 Bednárik 2017: 211.

21 Marchut 2014: 17. 
Die Vertreibung als Zäsur im religiös-kulturellen Leben...

kunftsland- oder Region. Was mit den aus der Sicht der Vertriebenen bzw. der bundesdeutschen Forscher und Forscherinnen „Daheimgebliebenen“, also den Nicht-Vertriebenen, nach 1946 passierte, findet weniger wissenschaftliche Aufmerksamkeit, sowohl aus bundesdeutscher als auch aus ungarischer Forschungsperspektive. Die Zeit der gravierenden Veränderungen, der Anpassung an die neuen Umstände wird in der Forschung oft missachtet. Obwohl die Vertreibung als Erfahrungszäsur zwar das Handeln der Menschen beeinflusste, ${ }^{22}$ setzten sich die Veränderungen nicht von einem Tag auf den nächsten durch. Jedoch wird die Vertreibung als Ereignis als „d[er] sichtbare[...] Einschnitt in eine[...] geschichtliche[...] Entwicklung “23, als Beginn einer ,neue[n] Zeitrechnung“24 interpretiert.

Diese Abgrenzung des ,gleichförmigen Zeitverlauf[es] der Vergangenheit [in] unterschiedliche Zeitabschnitte" 25 durch die Vertreibung als Zäsur entspringt aus dem in Ungarn vorherrschenden politischen System der Nachkriegszeit bis zur Wende 1989: „[P]olitische Brüche und soziale oder kulturelle Entwicklungen, mit denen sich Zeithistorikerinnen und Zeithistoriker

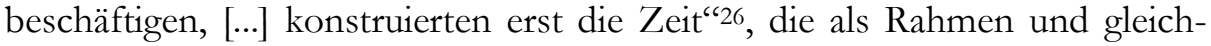
zeitig auch als Gegenstand der zu erforschenden Ereignisse bzw. als Forschungsgegenstand dienen. ${ }^{27}$ Denn Phasen der Geschichte werden aus Zeitgrenzen abgeleitet, ${ }^{28}$ historische Zeit „,[wird] [...] erst durch die untersuchten

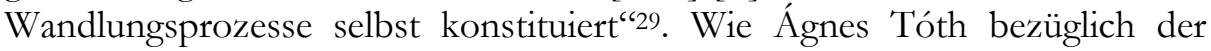
Forschungslage in Ungarn hervorhebt, „galt [die Vertreibung der Deutschen aus Ungarn] bis Mitte der 70-er, Anfang der 80-er Jahre für [sic] ein Tabuthema“"30. Die ersten Werke, die sich mit der Thematik auseinandersetzten, fokussierten u.a. auf „d[ie] politische[...] Verantwortung des Ungarndeutschtums während des Krieges, sowie d[en] außen- und innenpolitischen Hintergrund[...] der Umsiedlungen“"31. Einen Problemfall der Forschungen sieht Tóth darin, dass Oral History als Methode nicht zur Analyse der sozialen Umwälzungen nach der Vertreibung, sondern „,vorzüglich zur Ergän-

22 Sabrow 2014: o.S.

23 Sabrow 2014: o.S.

${ }^{24}$ Vgl. Kovácsné 2001: (2). „Erschienen in der Reihe Erzäblende Vergangenheit, im Jahr des 55. Jahrestages der Vertreibung." Hervorhebung durch die Verfasserin der Arbeit.

25 Sabrow 2014: o.S.

26 Graf 2012: o.S.

27 Graf 2012: o.S

28 Sabrow 2014: o.S.

29 Graf 2012: o.S.

30 Tóth 2010: 34.

31 Tóth 2010: 34. 
zung von fehlenden Angaben verwendet [wurde]“32. Die Interviews wurden „aus der Sicht der Erinnerungskultur nicht analysiert“33. Neben der Zwischenkriegszeit wurde auch die Nationalitätenpolitik nach 1950 untersucht, die Ereignisse während der Vertreibung wurden aber bisher nicht dahingehend erforscht. ${ }^{34}$ Wie Tóth formuliert: „[E]ine folgerichtige Fortführung von Debatten über die Begriffe - Aussiedlung - Vertreibung Flucht - Umsiedlung, kollektive und individuelle Verantwortung, Strafe und Bestrafung - fand nicht statt.“"35

\section{Historische Zäsuren in der Forschung}

„Historische Zäsuren besetzen eine prominente Rolle im geschichtlichen Denken. "36 Sie sind Reflexe des historischen Orientierungsbedürfnisses einer Gesellschaft. ${ }^{37}$ Deswegen ist es nachvollziehbar, dass die Etablierung der Vertreibung als Zäsur in Budaörs für viele der Betroffenen für den Neuanfang notwendig war, denn „nicht im Geschehen selbst stecken sie [Zäsuren, V. M.], sondern in ihrer zeitgenössischen oder nachträglichen Deutung“38. Manfred Berg macht die Beobachtung: ,Je mehr nachfolgende Ereignisse und Entwicklungen ohne das als Zäsur betrachtete Ereignis als sehr unwahrscheinlich gelten können, umso besser lässt sich der Zäsurcharakter begründen. “39 Diese Aussage könnte auch umgekehrt formuliert werden, indem man die Frage stellt, was möglich gewesen wäre, wäre der Großteil der Bevölkerung von Budaörs in den Jahren 1946-1947 nicht vertrieben worden. Die Vertreibung als heterodoxe Zäsur ,[stellte] den zeitgenössischen Erfahrungsraum gänzlich auf den Kopf [...] [und] die vorherrschende Weltsicht einer Gesellschaft und einer Zeit [...] in Frage" ${ }^{\text {" } 0}$. Martin Sabrow nennt auch andere Merkmale heterodoxer Zäsuren:

32 Tóth 2010: 39.

33 Tóth 2010: 39.

34 Tóth 2010: 40. Siehe dazu das neulich erschienene Buch von Ágnes Tóth. Tóth 2020.

35 Tóth 2010: 40.

36 Sabrow 2014: o.S.

7 Sabrow 2014: o.S.

38 Sabrow 2014: o.S.

39 Berg 2011: o.S

40 Sabrow 2014: o.S. 
Die Vertreibung als Zäsur im religiös-kulturellen Leben...

„[...] [Sie] erzwingen Neuinterpretationen, stellen Zeitgenossen vor Anpassungsprobleme, die den Gegensatz von biografischer Kontinuität und politischer oder sinnweltlicher Diskontinuität zu bewältigen verlangen.“"41

Was die Interpretation der Vertreibung in Budaörs als Zäsur angeht, lässt sich diese gleichzeitig als eine ,zeitgenössische[...] Erfahrungs- oder Ordnungszäsur“"42 und auch als „,nachträgliche[...] Deutungszäsur“443 beschreiben, letzteres, weil sie in der Historiografie wegen des politischen Systems eine Zeit lang nicht als Zäsur wahrgenommen werden konnte.

Wie András Grósz zu bedenken gibt, wurden die Ereignisse der Jahre 1944-1945 in Budaörs, ähnlich wie in vielen anderen Ortschaften, nicht umfassend erforscht. ${ }^{44}$ Die ortsgeschichtlichen Forschungen konzentrierten sich in ihren Abhandlungen auf das Ereignis der Vertreibung 1946, ${ }^{45}$ das auch im Zentrum von Rückerinnerungen und biografischen Interviews steht. ${ }^{46}$ „Die örtlichen Ereignisse während des Zweiten Weltkrieges wurden bislang stets als etwaige Ergänzung bzw. Vorgeschichte der Vertreibungsprozedur in den Jahren 1946-47 erwähnt. “47 - so Grósz in der Einführung seines Beitrags im Buch Entrecbtungen in Budaörs, das infolge der Arbeit einer 2007 in Budaörs gegründeten Forschungsgruppe zustande kam. Die Forschungsgruppe hatte das Ziel, den Zeitraum von 1944-1948, den eine ehemalige Mitarbeiterin der Deutschen Selbstverwaltung in Budaörs als „dunkles Kapitel [...], über das man nicht spricht" ${ }^{\text {"48 }}$ beschreibt, wissenschaftlich zu erforschen. Auch um diese Lücke zu füllen, beschäftigte sich Grósz in seiner Arbeit mit den Ereignissen in Budaörs am Ende des Zweiten Weltkriegs, „die der Budaörser Vertreibung unmittelbar vorausgingen "49. Bei den von der Forschungsgruppe durchgeführten Interviews und ihren Analysen wurde auf den historischen Aspekt der Ereignisse des untersuchten Zeitraumes fokussiert. Veränderungen im sozialen und kulturellen Leben der Gemeinde Budaörs wurden nicht detailliert erforscht. Um die Entwicklungen des kirchlichen Le-

\footnotetext{
41 Sabrow 2014: o.S.

42 Sabrow 2014: o.S.

43 Sabrow 2014: o.S.

44 Grósz 2010: 78.

45 Anm. der Verfasserin: Da der Großteil der Budaörser Vertriebenen, sieben von den insgesamt acht Transporten, im Jahr 1946 das Land verließ, wird der besseren Lesbarkeit wegen über die Vertreibung 1946 geschrieben. Selbstverständlich ist darunter auch der achte Transport im Jahr 1947, der in die Sowjetische Besatzungszone ging, zu verstehen.

46 Grósz 2010: 78.

47 Grósz 2010: 78.

48 Grósz (Hg.) 2010: (11).

49 Grósz 2010: 77.
} 
bens in Budaörs und der Festgestaltung besser nachvollziehen zu können, wird zuerst die Lage der katholischen Kirche im untersuchten Zeitraum vorgestellt.

\section{Die katholische Kirche in den Jahren 1945-1949}

Der Katholizismus der Koalitionsjahre 1945-1949 nährte sich aus der „katholischen Renaissance“ ${ }^{\circ 0}$ der Zwischenkriegszeit, die hauptsächlich von den religiösen Orden und deren breiter sozialer Basis getragen wurde. ${ }^{51}$ Die katholische Kirche Ungarns war im Laufe ihrer Jahrhunderte langen Geschichte immer eng mit der jeweiligen Regierung verbunden,52 ihre Rolle gewann während der ,christlich-nationalen“"Horthy-Zeit noch mehr an Bedeutung. Die Kirche als politische und soziale Akteurin beteiligte sich unter anderen auch an den staatlichen Feierlichkeiten. ${ }^{53}$ Dies änderte sich am Ende des Zweiten Weltkriegs: Das Land war in politischer sowie gesellschaftlicher Sicht zerrissen, seine historische Einheit konnte (zwar temporär) nur von der 900 Jahre alten ungarischen katholischen Kirche aufrechterhalten werden, 54 bis letzten Endes die Kirche langsam an ihrer politischen und gesellschaftlichen Bedeutung zu verlieren begann. ${ }^{55}$ Csaba Szabó gliedert die ersten 20 Jahre des Kommunismus in Ungarn von 1945 bis 1965 in sieben Epochen. Der Zeitraum, mit dem sich vorliegende Arbeit befasst, die Jahre 1945-1949, beschreibt Szabó als die Epoche, in der „die wirtschaftliche und gesellschaftliche Basis der Kirche zerstört [wurde] "56. Die Ausschaltung der Kirche aus dem öffentlichen Leben spitzte sich in den Schauprozessen gegen Kardinal Mindszenty und Erzbischof Grôsz zu. ${ }^{57}$ Ziel des sich etablierenden Regimes war in diesen fünf Jahren die Schaffung einer atheistischen Gesellschaft, die bereit war, sich in den Dienst der marxistischen Ideologie zu stellen. ${ }^{58}$ Die gläubigen Christen wurden unter dem Stichwort klerikale Reaktion gebrandmarkt und sukzessive verfolgt. ${ }^{59}$ Wie Szabó beobachtet, war während des

50 Gergely 1999: 180.

1 Gergely 1999: 180.

Szabó 2003: 13.

Gergely 1999: 93.

Klimó 2015: 262, 265.

Szabó 2003: 13.

5 Szabó 2003: 13.

Szabó 2003: 14.

Vgl. Szabó 2003: 18.

59 Vgl. Szabó 2003: 18. 
Die Vertreibung als Zäsur im religiös-kulturellen Leben...

Kommunismus in Ungarn „die kirchlich geprägte Alltagskultur stark kontrolliert und eingeschränkt" ${ }^{\text {" } 00}$. Jedoch konnte sich in diesem Zeitraum die katholische Kirche gewissermaßen als Widerstandskraft und Obhut für die Verfolgten etablieren. Dies war in erster Linie dem 1945 neuerlich ernannten Kardinal Mindszenty und seiner Tätigkeit zu verdanken. Der Erzbischof wurde in Ungarn nach der Wende zum Symbol des kirchlichen Widerstandes gegen den vierzig Jahre andauernden Sozialismus. ${ }^{61}$

József Mindszenty (1882-1975) wurde unter den Namen Pehm in Csehimindszent geboren. Nach Szabó soll er „[a]ls Zeichen seines Protestes gegen den Vorstoß des Nationalsozialismus nach Ungarn [...] 1941 seinen deutschlautenden Namen [abgelegt haben] "62. Als Erinnerung an seinen Geburtsort nahm er den Namen der Ortschaft an. ${ }^{63}$ Nach dem Tod des Kardinalprimas Jusztinián Serédi im Jahr 1945 ernannte Papst Pius XII. den Bischof von Vesaprém/Wesprim, József Mindszenty, zum Erzbischof von Esztergom/Gran. ${ }^{64}$ Mindszenty lehnte zeitlebens die Verhinderung der Rückkehr des Herrscherhauses Habsburg auf den Thron ab, sein Legitimismus wurde wegen seiner Position als erste Person der katholischen Kirche in Ungarn von den Kommunisten als politisches Programm interpretiert. ${ }^{65}$ Mindszenty kommt eine bedeutende Rolle in der ungarndeutschen Erinnerungskultur zu: Der Kardinal machte auf die Lage der deutschen Minderheit in Ungarn in einem Rundschreiben aufmerksam, protestierte gegen ihre Vertreibung, was von den Kommunisten als Sympathisieren mit den „,faschistischen Verschwörern" interpretiert wurde. ${ }^{66}$ Wie Szabó bereits im Vorwort seines Buches über den Kardinal hervorhebt: ,József Mindszenty ist eine der am meisten diskutierten Persönlichkeiten der ungarischen Geschichte.“67 Obwohl die Person Mindszenty, besonders wegen seiner Sympathie für die Habsburger und seiner Überzeugung, „dass ein König und das Königreich für Ungarn die beste Staatsform gewesen wäre" ${ }^{68}$, auch heute noch nicht unumstritten ist, lässt sich seine Rolle in der Schaffung einer neuen ungarischen katholischen Gesellschaft in den ersten Jahren nach dem Zweiten Weltkrieg nicht bestreiten. ${ }^{69}$

60 Szabó 2003: 20.

61 Klimó 2012: 137.

62 Szabó 2003: 31.

63 Szabó 2003: 31.

64 Szabó 2003: 29.

65 Szabó 2003: 31, 48.

66 Szabó 2003: 42-43.

67 Szabó (Hg.) 2012: 7.

68 Szabó (Hg.) 2012: 7.

69 Vgl. Hatos: 2012. 
Am 15. August 1947, an Mariä Himmelfahrt, wurde in Ungarn das Marianische Jahr eröffnet, das bis zum 8. Dezember 1948, dem Fest des Unbefleckten Empfängnis, dauerte. ${ }^{70}$ Ziel des von Mindszenty ausgerufenen Marienjahres war die Schaffung einer neuen ungarischen katholischen Gesellschaft, er führte gleichzeitig eine nationale und katholische Kampagne gegen das Regime. ${ }^{71}$ Klimó stellt fest: „Nach der Ausschaltung der politischen Opposition in den Jahren zwischen 1946 und 1948 wurde er [Mindszenty, V. M.] zum letzten und einflussreichsten innenpolitischen Gegner der Kommunisten. ${ }^{\text {"72 }}$ Seine „,nationalkatholische Agenda“73, die sich auf die Schutzpatronin von Ungarn, Patrona Hungariae, bezog, mündete in eine „verstärkte Marienfrömmigkeit“ ${ }^{\text {"74 }}$ in Form des Marienjahres. „Das ganze Land war im Sommer 1948 voll von Agitatoren der marxistischen Parteien und Gewerkschaften und der Volkskollegien" ${ }^{\text {"75 }}$, jedoch ist es Mindszenty gelungen, die Gläubigen gegen die Politik der Kommunisten zu mobilisieren: Hunderttausende besuchten die Veranstaltungen im Marienjahr. ${ }^{76}$ Klimó formuliert:

„Die im Sommer desselben Jahres [1948, V. M.] unter Parteichef Mátyás Rákosi errichtete stalinistische Diktatur sah schließlich kein anderes Mittel, den unbeugsamen Kirchenführer zum Schweigen zu bringen, als ihn unter der Anschuldigung, er wolle mit Hilfe imperialistischer Mächte die Habsburgermonarchie in Ungarn wiedererrichten, ins Gefängnis werfen zu lassen."

\section{Fronleichnam in Budaörs in den Krisenjahren}

Hans-Werner Retterath schreibt über die Bedeutung des Fronleichnamsfestes für die Budaörser in den Krisenjahren:

„Für die fast ausschließlich Budaörser war das Fronleichnamsfest mit seiner Prozession eines der höchsten Feste im kirchlichen und de facto auch weltlichen Jahreslauf, umgekehrt stellte die Fronleichnamsprozession auch die Repräsenta-

70 Szabó 2003: 60.

${ }^{71}$ Lemma „Mária-év" im Magyar Katolikus Lexikon [Ungarisches Katholisches Lexikon] http://lexikon.katolikus.hu/M/M\%C3\%A1ria-\%C3\%A9v.html und Klimó 2018: 257.

2 Klimó 2015: 257-258.

3 Klimó 2015: 258.

74 Klimó 2015: 258.

Szabó 2003: 67.

Klimó 2012: 136.

Klimó 2015: 257. 
Die Vertreibung als Zäsur im religiös-kulturellen Leben...

tion ihrer christlichen Religiösität schlechthin dar. Nach 1945 bildete sie in einer Zeit, die durch die Niederlage der NS-Ideologie und die aufkommende Furcht vor dem Kommunismus gekennzeichnet war, für viele den einzig verbliebenen moralischen Rettungsanker." ${ }^{\text {"78 }}$

Dies spiegelt sich in den Abhandlungen über das Fronleichnamsfest in den Jahren 1944-1946. Aufgrund der Bedeutung des Fronleichnamsfestes finden sich fast in allen lebensgeschichtlichen Erinnerungen und Interviews Aussagen über das Fest. Besonders überrepräsentiert sind die aus den Jahren 1944-1946. Es muss betont werden, dass aus den Jahren 1947 und 1948 keine Quellen zur Verfügung stehen, die als ähnliche Selbstaussagen ausgewertet werden könnten. Dies bestätigt wiederum die These, dass die Vertreibung sich sowohl in der Wissenschaft als auch in Budaörs als einzig mögliche Zäsur in der Festgestaltung etablierte. Auf das Fronleichnamsfest im Jahr 1944 wird oft als das letzte in ,alter“ Form reflektiert. Eine Gewährsfrau aus Budaörs, Theresia Noack, erzählt:

„Es war das letzte Fronleichnamsfest, das wir so gefeiert haben, wie es immer gefeiert wurde. Bei dieser großen Menschenmenge merkte man nicht, dass Hunderte von jungen Männern fehlten. Nur die betroffenen Angehörigen schmerzte es sehr, ohne die geliebten Menschen zu sein und diesen schönen Tag, der so reich an Sitten und Bräuchen war, ohne sie zu feiern. [...] Alles war so, wie es immer war. Wir waren 1944 noch freie Menschen. Wir trugen den Schmerz um die fehlenden geliebten Menschen mit Würde und innigem Gebet und Gesang. Im Herzen hegten wir die Hoffnung, dass sie zurückkommen würden, und dass der Krieg bald zu Ende sein würde. Dass ein Jahr später alles anders sein würde, konnten wir uns nicht vorstellen. Dies war das letzte unvergessliche Wuderscher Fronleichnamsfest von 1944.“79

Frau Noack hob im Interview immer wieder hervor, dass die Menschen damals noch nicht geahnt hätten, was später auf sie zukommen sollte: „Im Juli 1944 wussten wir noch nicht, dass dies alles noch auf uns zukommen würde. Rückblickend ist dieses Leid uns immer gegenwärtig." ${ }^{80} 1944$ als letztes Fronleichnamsfest in ,alter“ Form gewinnt erst an Bedeutung, wenn die Berichte über die Jahre danach ebenfalls analysiert werden. Ereignisse, die mit dem Fronleichnamsfest in Verbindung gebracht werden können, sind fest im kulturellen Gedächtnis der Budaörser und Budaörserinnen verankert. Der

78 Retterath 2011: 80. Hervorhebung wie im Original.

79 Kovács 2005: 23. Anm. der Verfasserin: Ein Auszug des Interviews wurde auch in Unsere Post, Heimatzeitung der Deutschen aus Ungarn gedruckt. Siehe: Herzog Res/Noack 2004: 22.

80 Kovács 2005: 25. 
(damals noch stellvertretende) Pfarrer von Budaörs, Zoltán Sík, wandte sich am 14. Juli 1945 in einem Brief an den Domvikar in Esztergom, János Drahos, und berichtete über die an Fronleichnam durchgeführte Razzia: „Die Fronleichnamsprozession in Budaörs wurde noch pompöser gefeiert, als gewohnt. Das Ende der Prozession wurde aber von einem peinlichen Zwischenfall gestört."81 Die von der bereits erwähnten Forschungsgruppe interviewten Gewährsleute wussten im Allgemeinen wenig über die Internierungen im Dorf, jedoch konnte die Erinnerung an die erste Razzia mit dem Fronleichnamsfest im Jahr 1945 verbunden werden. „Die erste war am Fronleichnam fünfundvierzig“"82 - berichtet Frau Z. in einem Interview, das Ágnes Kálmán zu ihrer Studie heranzog. Kálmán bekräftigt:

„Die erste Razzia traf die Bevölkerung an einem Sonntag, als der Blumenteppich zum Fronleichnamstag gelegt war. Nach Aussage einer Gewährsperson wählte die Polizei mit Absicht diesen Zeitpunkt, denn die meisten Männer hielten sich da auf demselben Platz auf: ,Zum Fronleichnam waren wir da, und am Sonntag waren wir draußen, und vor allem am Sonntag, wenn es ein solches Fest oder Ähnliches gab, nutzten die das aus. " 83

Kálmán hebt die Selektivität von Erinnerungen hervor: Erinnerungen an andere Internierungen seien zum Zeitpunkt der Interviews schon verwischt gewesen, während die am Fronleichnam durchgeführte erste Razzia im Jahr 1945 fest in der Erinnerung der Interviewten verankert war. ${ }^{84}$ „Sie wurden in Festtagskleidung interniert. “85 - hebt eine Gewährsperson hervor, wie auch die Tatsache, dass den Polizisten bekannt war, dass die jungen Männer, die sie suchten, sich an Fronleichnam, dem größten Fest des Gemeinde, zeigen. Darüber schreibt auch Grósz:

„Als Zeitpunkt für eine Razzia wurde jeweils eine sämtliche Einwohner in Budaörs bewegende Kirchenfeier, der Fronleichnamstag gewählt, wo alle einheitlich an der Prozession teilnahmen, und dies gab für Inhaftierungen eine entsprechende Gelegenheit." ${ }^{\text {"86 }}$

81 PL 2935/1945.

82 Anm. der Verfasserin: Zitat aus einem Interview mit Frau Z., 88 Jahre, am 08.03.2008, zitiert in Kálmán 2010: 343.

83 Kálmán 2010: 343-344. Anm. der Verfasserin: Der durch Kursivierung (wie im Original) hervorgehobene Satz ist ein Zitat aus einem Interview mit Frau Sz., die bei der Durchführung des Interviews am 31.05.2008 83 Jahre alt war. Vgl. Fn. 31. Kálmán 2010: 344.

84 Kálmán 2010: 344.

85 Kovács 2005: 62.

86 Grósz 2010: 95-96. 
Die Vertreibung als Zäsur im religiös-kulturellen Leben...

„Von der Zerschlagung der Prozession können die heimgebliebenen [sic] nach 50 Jahren noch immer sich entsetzt mit Tränen in den Augen erinnern. “87 Mindestens 150-160 Personen wurden interniert. 88

Im Budaörs Lexikon steht, dass die Tradition auch nach 1946 weitergeführt wird. ${ }^{89}$ Eine andere Quelle formuliert: „Auch nach der Vertreibung im Jahr 1946 lebt die Tradition weiter, der Teppich ist um die Kirche herum ,[ge]schrumpft[...]' (seine Länge beträgt 80 Meter). ${ }^{“ 90}$

Aus den Texten geht aber nicht hervor, ab wann sich die Prozession auf einen verkürzten Prozessionsweg um die Kirche herum beschränken musste. Jedoch lassen sich Aussagen finden, die das Jahr 1946 als Jahr der Veränderungen betrachten.

„Vor 56 Jahren, 1946 war alles zu Ende... die blühende Obstkultur, die sauberen Häuser und Straßen, die Volkstracht, die Blaskapellen, die herrlichen Kirchenfeste, die lustigen Kiritogs - und Faschingsbälle, die gemütlichen Stunden in der Weinstube zur Winterzeit... Von diesem einstigen in Wohlstand lebenden Budaörs konnte fast nichts gerettet werden, die kleine Zahl der noch dagebliebenen deutschen Bevölkerung hat lange Zeit schweigen müssen... “91

So formulierte Imre Ritter, Vorsitzender der Deutschen Selbstverwaltung in Budaörs, im Vorwort des Buches Auf steinigen Wegen. Wie das Zitat zeigt, wird die Auffassung, die Vertreibung im Jahr 1946 sei als Ende des Lebens in alter Form das Ende des „kultivierten“ Budaörs gewesen, auch auf offizieller Ebene kommuniziert. Wichtig ist diesbezüglich noch anzumerken, dass die Budaörser in insgesamt acht Transporten, in zwei Wellen vertrieben wurden. Obwohl der letzte Transport Budaörs erst 1947 verließ, wird hier - wie anderenorts - über die Vertreibung im Jahr 1946 als die einzige geschrieben.92

Wie aus dem oben Angeführten hervorgeht, kann für die Veränderung in der Festgestaltung nicht eine Zäsur gesetzt werden. Die Anpassung an die neuen sozialen und politischen Umstände verlief stufenweise. So musste 1944 damit umgegangen werden, dass viele Männer an der Prozession nicht präsent waren und dadurch an den Vorbereitungen des Festes nicht teilnehmen konnten. Trotz dieser Tatsache wird von Frau Noack auf das Fronleichnamsfest im Jahr 1944 als das letzte in „alter“ Form hingewiesen. Die aus

87 Wittinghoff (Hg.): 58

88 Grósz 2010: 96.

89 Filipszky-Grósz 2009: 141.

90 Kovácsné 2001: 81.

91 Steinhauser 2002: 6.

92 Marchut 2010: 224. 
politischen Gründen unterbrochene Prozession und die durchgeführte Razzia bzw. die Internierungen im Jahr 1945 verankerten sich als gewaltsame Eingriffe in das schönste und wichtigste Fest des Dorfes ins kollektive Gedächtnis von Budaörs. Wie im Buch Die Wurzeln wachsen tief formuliert wird, begann die Vertreibung in Budaörs bereits mit der Razzia am Fronleichnamstag 1945. ${ }^{3}$ Über das Fronleichnamsfest im Jahr 1946 ist wenig bekannt, es wird von der Tatsache der Vertreibung überhöht, deren Grausamkeit und Ungerechtigkeit in alle Bereiche des Alltagslebens hineinprojiziert wird, wodurch diese sich als Zäsur in der Festgestaltung etabliert, nach der nichts mehr in „alter“ Form möglich war. Während Heimatvertriebene ihre Heimat sowohl sozial als auch räumlich verlieren, bedeutete für Nichtvertriebene die Vertreibung ebenfalls einen Heimatverlust, und zwar in sozialer Hinsicht. Obwohl sie in Budaörs bleiben durften, gingen ihre alten sozialen Kontakte und familiäre Beziehungen verloren. ${ }^{94}$

\section{Kirchlich-religiöses Leben nach der Vertreibung}

Nach Angaben von Grósz, die auf Verwaltungsdokumenten im Pest Megyei Levéltár (Archiv des Komitats Pest) basieren, kamen die sowjetischen Truppen am 26. Dezember 1944 in Budaörs an. ${ }^{95}$ Über die Folgen der Invasion schreibt Grósz: „Infolge der seit Ende Dezember 1944 fortdauernden sowjetischen Besatzung begann das Gemeindeleben sich zu erodieren, der Kreislauf der Dorfwirtschaft verlangsamte sich." "96 In den Jahren 1944-1945 verließen Budaörs insgesamt ca. 2500-3000 Menschen: ${ }^{97}$ Ein Teil schloss sich freiwillig oder unter Zwang der „Schutzstaffel“ (SS) an, andere flüchteten, nachdem sie vom Anmarsch der sowjetischen Truppen erfuhren, nach Westen. ${ }^{98}$ Budaörs wurde zuerst von den Deutschen, dann von den Sowjets belagert, wodurch die Ortschaft sich durchgängig in einem Kriegszustand befand. Grósz stellt fest:

„Die sich in Budaörs entfachten [sic] Kriegsereignisse und deren Folgen wühlten das geschlossene Gemeindeleben von Grund auf. Für den seine deutschen Wurzeln und Traditionen pflegenden, dabei aber zu [sic] seiner ungari-

93 Wittinghoff (Hg.): 56.

${ }_{94}$ Vgl. Faehndrich 2003: 196-197.

95 Grósz 2010: 88.

96 Grósz 2010: 89.

97 Grósz 2010: 104.

98 Grósz 2010: 104. 
Die Vertreibung als Zäsur im religiös-kulturellen Leben...

schen Heimat treu gebliebenen Menschen wurde die eigene Identität in Frage gestellt, weil der Krieg und die 1945 angefangenen [sic] Rechtsverlust bewirkenden Maßnahmen, sowie die außen- und innenpolitische Lage des Landes die im Laufe der Jahrhunderte vor Ort herausgestalteten [sic] alltäglichen Strukturen untermauerten [sic], und die Vertreibung 1946 aus der Sicht des Gemeinschaftslebens die Siedlung bereits in einem abgeschwächten Zustand traf.“ ${ }^{\text {(99 }}$

Im Zuge der Vertreibung wurden 90\% der Bevölkerung, insgesamt ca. 8300 Menschen, in sieben Transporten in die amerikanische Besatzungszone, in einem Transport im August 1947 in die sowjetische Besatzungszone vertrieben. ${ }^{100}$

„Die Siedlung [Budaörs, V. M.] hatte ein reges Vereinsleben, das religiöskirchlich geprägt und durch Selbstorganisierung wie auch Selbständigkeit gekennzeichnet war." "101 Das Alltagsleben in Budaörs war nicht nur vor dem Zweiten Weltkrieg, sondern auch während der schwierigsten Zeiten durch tiefen Glauben und die religiösen Sitten und Bräuche bestimmt. Bevor das in der Einleitung bereits erwähnte Album, dass Kardinal Mindszenty anlässlich der Firmung im Jahr 1948 geschenkt wurde, vorgestellt wird, soll im Folgenden in einem kurzen Überblick das kirchlich-religiöse Leben der Zeit auf der Mikroebene geschildert werden.

Eine der letzten Firmungen vor seiner Festnahme im Dezember erteilte der Fürstprimas im Sommer 1948 in Budapest: Er besuchte zwischen dem 26. Mai und dem 2. Juni nur eine Pfarrei pro Tag, um diese besser kennenzulernen und dadurch zu einem besinnlicheren Fest beizutragen. ${ }^{102}$ Wie aus dem Schriftwechsel mit den betroffenen Pfarreien hervorgeht, drängte Mindszenty auf eine baldige Abhaltung der Firmungen, um sicherzustellen, dass diese noch stattfinden können. Ziel von Mindszenty war auch, möglichst vielen die Firmung zu spenden. ${ }^{103}$ Jedes Kind, das bereits zur heiligen Kommunion zugelassen worden war, durfte die Firmung erhalten. ${ }^{104}$ Budaörs war ursprünglich nicht auf der Liste der zu besuchenden Pfarreien. Die Firmungsreise beschränkte sich im Frühling bzw. im Frühsommer auf Pfarreien in Budapest. Zoltán Sík, der Pfarrer aus Budaörs wandte sich am 2. September 1947 in einem Brief an Kardinal Mindszenty, um Budaörs auf die Liste aufnehmen zu lassen, mit dem Argument, dass in Budaörs seit 1939

\footnotetext{
99 Grósz 2010: 105.

100 Filipszky-Grósz 2009: 100-101.

101 Grósz 2010: 79.

102 PL 4455/1948

103 PL $4455 / 1948$

104 PL 4455/1948.
} 
keine Firmung mehr gespendet worden war. Sík schrieb: „Ich bitte Sie darum schon jetzt, weil die Vorbereitungen im jetzigen Zustand der Gemeinde eine große Arbeit bereiten, mit der ich zeitnah anfangen möchte.“105 Mit „Zustand" sind wohl die durch den Zweiten Weltkrieg verursachten Schäden, mitunter die Vertreibung gemeint. Die schwere Situation in Budaörs war dem Kardinal bekannt. Der frühere Pfarrer, Miklós Aubermann, war bekanntlich im örtlichen Volksbund tätig gewesen und hatte unter den Dorfbewohnern aktiv um SS-Mitglieder geworben.106 Marchut formuliert: „Bei Missbrauch des tiefen Gottesglaubens seiner Gläubigen war ihm gelungen, einen Teil von ihnen in den Dienst des Nationalsozialismus zu stellen und gegen ihre ungarische Heimat zu wenden. "107 Nach der Flucht von Aubermann im Herbst 1944 leitete Sík, der frühere Pfarrvikar, die Pfarrei von Budaörs, bis er letztlich im Frühjahr 1946 zum Pfarrer ernannt wurde.108 Sík bedankte sich bei Mindszenty am 7. Februar 1946 für seine Ernennung und berichtete über die begonnene Vertreibung. ${ }^{109}$ Er formulierte sein persönliches Ziel, zum seelischen Wiederaufbau der Budaörser beizutragen und das kirchliche Leben neu zu organisieren. ${ }^{110}$ Das religiöse Leben im Dorf war nach der Ernennung von Sík vom Wiederaufbau und dem Wiedererstarken des Glaubens geprägt. Neben den kirchlichen Feiern und dem Vereinsleben zeigte sich das auch in der Firmung am 19. Juni 1948. ${ }^{111}$

\section{Alben in der Forschungspraxis}

Warum eben ein Album als Geschenk für den Kardinal angelegt wurde, soll durch einen theoretischen Überblick zu der Funktion und den Merkmalen von Alben ergründet werden. „Die Entscheidung, ein Album anzulegen, geht mit dem Wunsch einher, die Dinge in eine Ordnung zu bringen. " 112 - formulieren Anke Kramer und Annegret Pelz in der Einleitung des Bandes mit dem Titel Album: Organisationsform narrativer Kobären₹. Ein Album ist also eine Ordnungsform, ist aber gleichzeitig auch eine Kulturtechnik. ${ }^{113}$

\footnotetext{
105 PL 5951/1947.

106 Marchut 2010: 228.

107 Marchut 2010: 228.

108 Marchut 2010: 227.

109 PL 981/1946.

110 PL $981 / 1946$.

111 Album (23).

112 Kramer-Pelz 2013: 12.

113 FOTO | ALBUM.
} 
Die Vertreibung als Zäsur im religiös-kulturellen Leben...

Ziel der Gestalter und Gestalterinnen eines Albums ist es, Dinge wie lose Fotos, Eintrittskarten, Briefe u.v.a.m. zu einer eigenständigen Sammlung zusammenzuführen: „Der Einband rahmt das disparate Material und organisiert es zu einem kohärenten Ensemble.“114 Die meisten Alben befinden sich im Privatbesitz, jedoch sind sie auch in Archiven zu finden - bzw. nicht zu finden, denn: „In Archiven führen die Alben ein meist uninventarisiertes Schattendasein." ${ }^{115}$ Sie sind oft nicht als eigenständige Konvolute, sondern - wenn überhaupt - sind deren Inhalte, besonders, wenn es um Fotos geht, in die Beständen aufgenommen. Ute Holl schreibt:

„Das Album zeichnet sich dadurch aus, dass es eine Fläche oder Oberfläche darstellt für die Konstellierung von Bildern, Klängen oder Texten. Das heißt auch, nicht das einzelne Bild, sondern die Logik des Verhältnisses der Bilder, ihre Folge und Abfolge, ihre Zwischenräume charakterisieren das Album“"116.

Fotos erhalten oft erst in einem Zusammenhang mit anderen eine Bedeutung, daher ist bei der Analyse von Fotos als Quellen, die in Alben untergebracht sind, die Betrachtung des Albums als eigenständiges Werk unerlässlich. Aus diesem Grunde sollten Albuminhalte, vor allem Fotos nicht einzeln, sondern in den jeweiligen Alben eingebettet in Archive aufgenommen werden, denn nicht nur den Fotos, sondern auch den Räumen zwischen ihnen kann eine Bedeutung zugeschrieben werden. ${ }^{117}$

Alben können auch als Gegenarchive aufgefasst werden:

„Wenn es in kulturellen Krisen und Migrationssituationen notwendig wird, dem herausgerissenen Gedächtnis ein Medium zu widmen, übernehmen portative, kleinformatige oder digitale Alben die Funktion von Gegenarchive, Korrektiven und Ergänzungen des historischen Archivs. “118

Erreicht ein Ereignis die Schwellgrenze der Schriftlichkeit nicht, entsteht kein Schriftwechsel zwischen Behörden, der das Ereignis dokumentieren könnte. So kommt es dazu, dass das Ereignis in den Beständen eines Archivs komplett fehlt. Möchte man über das Alltagsleben der Menschen mehr erfahren, sind Archive (oft) nicht die fruchtbarsten Orte dafür. So konnten über die von Kardinal Mindszenty im Jahr 1948 erteilte Firmung in Budaörs, bis auf die Tatsache, dass diese stattgefunden hat, aus den Beständen des Eræz̧bischöflichen

114 Kramer-Pelz 2013: 12.

115 Pagenstecher 2009: o.S.

116 Holl 2013: 94.

117 Holl 2013: 94-95.

118 Kramer-Pelz 2013: 16. 
Viketória Muka

Archivs (Esætergomi Prímási Levéltár) in Esætergom/Gran kaum Informationen ermittelt werden. ${ }^{119}$ Das Album, das im Folgenden beschrieben und analysiert werden soll, fand sich nach mündlicher Nachfrage im Archiv unter Materialien zu den Fronleichnamstraditionen in Budaörs. Bevor das Album als Quelle für sich verändernde Fronleichnamstraditionen in der Nachkriegszeit sowie als Gegenarchiv zum Archiv der politischen und gesellschaftlichen Entwicklungen auf Makroebene analysiert wird, soll kurz auf die „identitätsstiftende Funktion des Albums" "120 und seine Rolle bei der Strukturierung und Konstruktion der Erinnerung eines Kollektivs eingegangen werden.

Kramer und Pelz heben überdies hervor:

„In Enteignungs- und Vertreibungskatastrophen übernimmt das kleinformatige Album für das herausgerissene Gedächtnis die Funktion des notwendigen medialen Bezugspunktes, auf den sich alle Memorialfunktionen konzentrieren." ${ }^{\prime 21}$

Das Anfertigen eines Albums verfügt „durch das sinnproduzierende Auswählen und Arrangieren von Bildern in Kombination mit Text und auch mündlicher Erzählung "122 über eine identitätsstiftende Funktion. Die Gedächtnisfunktion des Albums besteht darin, dass es mit der Darstellung des religiösen Lebens in Budaörs in „alter“ Form „als Gedächtnisstütze die Vergegenwärtigung des Vergangenen" 123 ermöglicht und zwar nicht nur beim Rezipienten, sondern in diesem Fall auch bei den Produzentinnen des Albums. ${ }^{124}$ Die Beteiligung der Barmberzigen Schwestern des Heiligen Vinzenz, von Paul, die die Mädchenschule in Budaörs leiteten und dadurch einen bestimmten Einfluss auf das religiöse Leben im Dorf ausübten, am Anfertigen des Geschenks ist eine mögliche Hypothese, die bisher weder entkräftet, noch bewiesen werden konnte. Jedoch ist ihre Beteiligung am Gestaltungsprozess des Konvolutes als Initiatorinnen und Organisatorinnen ohnehin möglich. Eine andere mögliche Hypothese ist, dass diejenige, die 1948 die Firmung erhielten, sich in dieser Form der visuellen Memoria beim Kardinal bedankten. Bei der Produktion des Albums wird von einer kollektiven Genese ausgegangen.

119 Anm. der Verfasserin: Dies mag auch mit den Restriktionen zusammenhängen, die den Zugang zu Forschungsmaterial im Eræ̧bischöflichen Archiv maßgeblich erschweren.

120 Kramer-Pelz 2013: 15.

121 Kramer-Pelz 2013: 14.

122 FOTO | ALBUM.

123 Eybl 2013: 200.

124 Anm. der Verfasserin: Es wird davon ausgegangen, dass das Album von Frauen, eventuell unter der Leitung des Pfarrers Zoltán Sík, angelegt wurde. 
Die Vertreibung als Zäsur im religiös-kulturellen Leben...

\section{Das Album als Quelle}

Das Album, das im Folgenden beschrieben werden soll, befindet sich im Erzbischöflichen Archiv in Esztergom. Es besteht aus 24 schwarzen Kartonblättern und beinhaltet insgesamt 45 Fotos, die sich alle auf den jeweiligen Rectos befinden. „Fotografien [...] sind allgegenwärtige Objekte des Schenkens, des Andenkens und des Austausches." 125 Das Album als gruppenspezifische Form der Erinnerung erzählt fragmentarisch das reiche religiöse Brauchtum in Bildern und verfügt mit Fotos von der Firmung auch über eine Memorialfunktion. ${ }^{126}$ Im Album findet sich das autobiografische Erzählmuster des Dorfes, mit Fokus auf seine wichtigsten religiösen Bauten und Traditionen. Es ist nicht als Album in den Bestand des Archivs aufgenommen worden: Die Bilder sind mit Bleistift durchnummeriert worden und sind einzeln unter den Inventarnummern Nr. 3895-3939 verzeichnet. Auf dem Deckblatt ist das Wappen von Kardinal Mindszenty zu sehen. Die vierfarbige Wappenmalerei (rot, gelb, blau, mit weißen Außenlinien) mit dem Motto des Kardinals, Pannonia Sacra (Heiliges Ungarn), nimmt den Hauptteil des Blattes ein: Es ist in der Mitte der Seite platziert und steht im Übergewicht zum Text auf der gleichen Seite. Das Wappen wird vom folgenden, weiß geschriebenen Text umrahmt: „Legföbb Pásætorunknak: budaörsi bivei. [Unserem obersten Hirten: seine Budaörser Gläubigen.]" Somit lässt sich Kardinal Mindszenty als Adressat des Albums identifizieren. Das Album beinhaltet auch vier Fotos von der Firmung (Nr. 3936-3939), zu deren Anlass das Album angefertigt wurde. So viel ist über seine Provenienz bekannt. Wann das Album ins Archiv gekommen ist, ist nicht bekannt. Im Pfarrarchiv in Budaörs befindet sich eine Danksagung von Kardinal Mindszenty an Pfarrer Sík vom 8. Juli. „Ich bedanke mich für das schöne, anlässlich der Firmung in Budaörs zugeschickte Album."127 Das Album muss also irgendwann zwischen dem 19. Juni und dem 8. Juli, also relativ zeitnah, in Esatergom angekommen sein.

Obwohl den Inhalt des Albums überwiegend das Medium Foto ausmacht, ist es kein Fotoalbum. Das Album, im Gegensatz zum verengten Begriff „Fotoalbum“, ist kein „konservatives Medium“128, wie man klassische Fotoalben von bürgerlichen Familien nennt. Matthias Bickenbach stellt fest, dass

125 Hirsch 2013: 128.

126 Kramer-Pelz 2013: 14.

127 BRKEI Sc. Anm. der Verfasserin: Im BRKEI war die Sichtung der Archivalien nicht gestattet, diese konnten durch Ermittlung des Direktors des Bischöflichen Archivs in Székeesfehérvár/Székesfehérvári Püspöki és Székeeskáptalani Levéltár, Dr. Gergely Mózessy, im Archiv gesichtet werden. Hervorhebung im Zitat durch die Verfasserin der Arbeit.

128 Bickenbach 2013: 107. 
die Funktion dieser Fotoalben zumeist auf das Speichern beschränkt ist, ${ }^{129}$ während Alben nicht nur die Aufgabe haben, Bilder zu speichern, sondern auch Kollektive konstituieren. ${ }^{130}$ Wie Bickenbach meint,

„[stellt] der vorherrschende Begriff als Fotoalbum und ,Bilderbuch' eine Verengung auf eine bestimmte Form und Ordnung dar [...], die dem kreativen Potenzial und der historischen Vielfalt des Albums nicht gerecht wird."131

Das Album beinhaltet neben den Fotos auch gemalte Verzierungen und kurze Texte, die nicht nur als begleitende Paratexte zu den Bildern, sondern auch als kommentierende Verständnistexte gelesen werden können. Die Bildbeschreibungen sind alle in ungarischer Sprache verfasst. Die allegorischen Motive dienen als Ergänzungen zu den jeweiligen Fotos. Diese kleinen gemalten Bilder tragen nur für diejenige eine Bedeutung, die das res pictae, also die Geschichte der Bilder, kennen. ${ }^{132}$ Die grafische Rahmung mit Ornamenten sowie die anderen Gestaltungselemente sind neben den Fotos ebenfalls als Informationsträger aufzufassen. Sie weisen über die Fotos hinaus und enthalten ergänzende Angaben zum religiösen Leben im Dorf. Der Aufwand, der bei der Bemalung der Seiten getrieben wurde, erstaunt auf den ersten Blick.

In der Einleitung des bereits zitierten Werkes, das sich mit Alben als Organisationsformen beschäftigt, wird auf ihre kohärenzstiftende Funktion hingewiesen:

„Entscheidend für die lebendige Aussage eines Albums ist, dass dieses vor allen Fragen nach Textkohärenz bereits auf der Objektebene allein dadurch Kohärenz stiftet, dass innerhalb seines Rahmens bestimmte wiederkehrende Dinge und Formate als Referenzträger und als Spuren von Handlungen, Ereignissen und Begegnungen wiederholt in Erscheinung treten. “"133

Der narratologische Faden, der die Bilder im Album miteinander verbindet, ist die Charakteristik der abgebildeten Bauten und Ereignisse als jene, auf die die Budaörser und Budaörserinnen besonders stolz waren. Die Ortschaft war vor dem Zweiten Weltkrieg für ihre Passionsspiele als das „Ungarische Oberammergau“, als Wallfahrtsort oder als Pfirsichparadies bekannt. Fotos, die

\footnotetext{
129 Bickenbach 2013: 108.

130 Kramer-Pelz 2013: 41.

131 Bickenbach 2013: 107.

132 Vgl. Schnabel 2013: 223.

133 Kramer-Pelz 2013: 13.
} 
Die Vertreibung als Zäsur im religiös-kulturellen Leben...

dieses Image untermauern, fanden auch Eingang ins Album. „Anordnung und Annotation der Fotos verweisen auf das Album als Narrationsraum für subjektive Konstruktionen von Erinnerung." "134 Die Anordnung in diesem Falle erfolgt durch eine thematische Clusterbildung: Zuerst werden die kirchlichen Bauten der Gemeinde (Nr. 3895-3900), die Steinbergkapelle, das Pfarramt und die Kirche abgebildet. Danach kommen, an prominenter Stelle die Fotos vom Fronleichnamsfest 1948 (Nr. 3901-3918), gefolgt von Bildern von den Passionsspielen auf dem Steinberg in den 1930er Jahren (Nr. 39193927), vom Sommercamp der katholischen Jugend in Adony (Nr. 3928-3929) und von der Heiligen Messe im Camp (Nr. 3930). Darauf folgt ein Gruppenfoto von Mitgliedern der Marienkongregation mit zwei Schwestern, die beide ein Cornet tragen (Nr. 3931). Es kommen Bilder von der Pfirsichausstellung im Jahr 1936 (Nr. 3932-3935). ${ }^{135}$ Schließlich kommen vier Fotos von der Firmung am 14. Juni 1948 (Nr. 3936-3939).

Bei der Analyse des Albums gilt „das hauptsächliche Interesse den Wahrnehmungs- und Deutungsmustern, also mehr der Art des bildlichen Erzählens als den Fakten des Erzählten selbst"136. Das Album ist als „visueller Text“ zu verstehen, „der aus ,Geschehen“,Geschichte“ macht und seine Kohärenz und Dynamik aus der Anordnung gewinnt." "137 In diesem Zusammenhang lassen sich gewisse Ähnlichkeiten zur „Schriftenklasse“138 Heimatbuch erkennen. Wie Heimatbücher der Vertriebenen, entstehen Alben in ihrer endgültigen Form durch „Auswahl, Reihung, Anordnung und Kommentierung der fotografischen Erinnerungen" ${ }^{139}$. Ähnlich wie bei den Heimatbüchern geschieht hier eine Kanonisierung der Inhalte: Die Frage, was in das Album kommen soll, hat eine identitätsstiftende Funktion für die Produzenten und Produzentinnen. Die Frage: „Was dürfen wir nicht vergessen?“‘140 ist charakteristisch für Gedächtnisgemeinschaften. Diese Frage

„[ist] so zentral für Identität und Selbstverständnis [...], dass die kollektiven Vergangenheitsbezüge stärker kulturell geformt und damit gefestigt werden müssen, um die (politische) Handlungsfähigkeit der Gruppe sicherzustellen. “141

\footnotetext{
134 Fremde im Visier.

135 Steinhauser 2007: 31.

136 Pagenstecher 2009: o.S.

137 Tippner 2013: 326.

138 Faehndrich 2011: 5, 44-68.

139 Pagenstecher 2009: o.S.

140 Sabrow 2014: o.S. Vgl. Moller 2010: o.S

141 Sabrow 2014: o.S.
} 
Viketória Muka

Gleichzeitig wird durch das Anlegen des Albums auch bestimmt, was sich ins Gedächtnis des Betrachters, in diesem Fall von Kardinal Mindszenty, über das Dorf einprägen sollte. Mit der Unterbringung der Fotos von der Firmung wird eine persönliche Nähe zur Ortschaft und zu den Gläubigen von Budaörs hergestellt. Das Album, in der Form, in der es angelegt wurde, ist nur für diejenige verständlich, die das Dorf und seine Geschichte kennen. Die Filiale Budaörs gehörte damals noch zum Erzbistum Esætergom, daher in den Zuständigkeitsbereich von Erzbischof Mindszenty. Dadurch waren ihm das Dorf und die wichtigsten religiösen Traditionen im Jahreslauf bekannt und es bedurfte keiner umfassenden Kontextualisierung und Erklärung der Bilder.

Im Album sind insgesamt 18 Bilder vom Fronleichnamsfest im Jahr 1948 untergebracht, die sich auf den Rectos 5 bis 14 befinden. Die oft ritualisierten Bilder von Blumenteppichen und ihren Mustern bilden das wichtigste und größte Quellenkorpus der Erforschung der Fronleichnamstraditionen in Budaörs, dadurch überrascht es nicht, dass diese im Album auch überrepräsentiert sind. Auf Recto 5 befinden sich ein nachkoloriertes Foto vom Blumenteppich (Nr. 3901), eine Glocke mit der Jahreszahl 1948 sowie ein Foto von der Mädchenschule (Nr. 3900) und eine gezeichnete Schulbank. Dadurch lässt sich darauf schließen, dass die Schülerinnen der Schule sich am Anfertigen des Albums beteiligten. Auf Recto 6 befinden sich zwei Fotos von der „Fronleichnamsprozession in Budaörs im Jahr 1948“ (Nr. 3902, Nr. 3903) und zwei Zeichnungen, ein stilisierter Blumenstrauß und die weiße Flagge der Marienmädchen mit der Heiligen Maria und dem Jesuskind. Auf Recto 7 folgen je ein Foto von einem der vier Altäre (Nr. 3904) und vom Blumenteppich (Nr. 3905). Auf Recto 8 folgen wiederum zwei Bilder. Auf dem einen ist die Segnung einer der Kapellen (Nr. 3906), auf dem anderen wiederum der Blumenteppich zu sehen (Nr. 3907). Die Seite ist verziert mit einem goldenen Räuchergefäß mit blauem Weihrauch sowie einem gemalten Altar mit der Monstranz zwischen zwei Blumensträußen und Kerzenleuchtern. Auf Recto 9 ist eine Aufnahme vom Blumenteppich zu sehen, mit einem Dominikanerkreuz (Lilienkreuz) und der Aufschrift „Credo“, die für das apostolische Glaubensbekenntnis steht (Nr. 3908). Daneben befindet sich eine Aufnahme von einem Altar (Nr. 3009), vor dem aus Blumen die Inschrift „Ich glaube an den endgültigen Sieg der Liebe", aus dem Glaubensbekenntnis von Ottokár Prohászka, dem Bischof von Székesesfehérvár/Stuhlweißenburg von 1905-1927, ausgelegt ist. ${ }^{142}$ Auf Recto 10 und 12 sind je zwei Fotos vom Blumenteppich und der Prozession (Nr. 3910, Nr. 3911, Nr. 3914, Nr. 3915), auf Recto 14

142 Lemma „Prohászka Ottokár“ im Magyar Katolikus Lexikon [Ungarisches Katholisches Lexikon]. http://lexikon.katolikus.hu/P/Proh\%C3\%A1szka.html 
Die Vertreibung als Zäsur im religiös-kulturellen Leben...

ein Foto (Nr. 3918) zu finden. Auf dem letzten Foto ist ein Doppelkreuz mit einer leider nicht lesbaren Schrift zu sehen. Da diese Fotos für die Beschreibung des Festes nicht über eine besondere Bedeutung verfügen, wird auf ihre Analyse im Rahmen der vorliegenden Arbeit verzichtet. Viel stärker bedeutungstragend sind die Fotos, die im Folgenden kurz beschrieben werden.

Auf Recto 11 sind ein Teppich-Muster mit der ungarischen Aufschrift „Zur Ehre Gottes“ (ung. „Isten dicsöségére") und das Kossuth-Wappen, das in den Jahren 1946-1949 als offizielles Wappen von Ungarn fungierte (Nr. 3912), zu sehen. ${ }^{143}$ Das Wappen, das in einer Zeit, in der die Mitglieder der deutschen Minderheit in Ungarn sukzessive verfolgt wurden, eine bedeutende Repräsentations- und Demonstrationsfunktion hatte, kann als Ausdruck der ungarischen nationalen Identität der Produzenten und Produzentinnen des Teppichs verstanden werden. Auf der gleichen Seite ist wiederum ein Foto von der Prozession (Nr. 3913) zu sehen. Fotos sind Reflexe des Zeitraumes, in dem sie entstanden sind. ${ }^{144}$ Anhand des Albums und der einzelnen Fotos sowie Bildunterschriften lässt sich feststellen, dass die Zäsur der Vertreibung im Album nicht explizit zum Ausdruck kommt. Dadurch lässt sich darauf schließen, dass das Leben nach der Vertreibung, selbstverständlich nicht unverändert, aber wieterging. Die Bestrebung, die alte Sozialstruktur und das kirchlich-religiöse Leben in ,alter“ Form, trotz der Abwesenheit vieler Brauchträger und Brauchträgerinnen aufrechtzuerhalten, lässt sich im Album beobachten. Trotzdem lässt sich feststellen, dass für diejenige, die die Tradition sowie frühere Bildaufnahmen kennen, die Abwesenheit des Großteils der ungarndeutschen Bevölkerung des Dorfes auf den ersten Blick auffällt. Die Abwesenheit der Budaörser Frauen und Mädchen in ihren Volkstrachten in der Prozession fällt auch ins Auge. Die Zahl der Trachtenträger und Trachtenträgerinnen beschränkt sich auf einige wenige Personen, die auf den Fotos abgebildet sind. Des Weiteren lassen sich deutlich weniger Zuschauer und Zuschauerinnen auf den Fotos finden als bei früheren Fronleichnamsprozessionen. Das sind Belege dafür, dass die Bilder vom Fronleichnamsfest tatsächlich 1948 entstanden sind, und nicht Fotos von früheren Anlässen verwendet wurden. Daneben ist ein Foto auf Recto 13 ebenfalls ein Beweis dafür, dass die Bilder tatsächlich aus dem Jahr 1948 stammen: Auf dem Foto ist das Bild mit dem Wappen des Eucharistischen Weltkongresses 1938 in Budapest mit den Jahreszahlen 1938-1948 versehen. ${ }^{145}$ Jedoch überrascht die Tatsache,

143 Vgl. Albert 2014.

144 Hirsch 2013: 130.

145 Anm. der Verfasserin: Die letzten zwei Ziffern von der Jahreszahl 1948 sind schwer zu lesen, anlässlich des zehnten Jubiläums des Festes kann aber davon ausgegangen werden, dass es sich um diese Ziffern handelt. 
dass auf den Fotos aus dem Jahr 1948 der alte Prozessionsweg mit den Altären zu erkennen ist. Wie das Album zeigt, wurde 1948 die Vertreibung als Zäsur in der Festgestaltung nicht in der Form wahrgenommen, wie wir es uns heute vorstellen. Der Prozessionsweg lief damals noch auf der Hauptstraße, entlang deren auf den Fotos alle vier Altäre erkennbar sind. Somit ist die Ansicht, mit dem Jahr 1946 und der Vertreibung als Zäsur hätte sich die Festgestaltung geändert und der Prozessionsweg um die Kirche herum beschränkt, widerlegt. Bis wann sich die Prozession auf der Hauptstraße aufrechterhalten konnte, ließ sich aufgrund mangelnder Quellen noch nicht genau ermitteln und bedarf daher wieterer Untersuchung.

\section{Fazit und Ausblick}

Budaörs kommt eine bedeutende Rolle in der ungarndeutschen Erinnerungskultur zu: Seit dem 18. Juni 2016 befinden sich dort die Landesgedenkstätte und das Denkmal zur Erinnerung an die Vertreibung. Réka Marchut versteht Budaörs als Symbol für die Vertreibung des Deutschen nicht nur aus dem Ofner Bergland, sondern aus ganz Ungarn. ${ }^{146}$ Wie die vorliegende Arbeit gezeigt hat, muss die Vertreibung nicht unmittelbar in allen Lebens- und somit auch nicht in allen Forschungsbereichen als einzig gültige Zäsur umgesetzt werden - auch wenn es sich unwahrscheinlich anhört.

„Ihre Plausibilität lässt sich aber nur in einem ständigen Prozess der Diskussion ausloten. Deshalb sind Urteile über historische Themen und eben auch über Zäsuren nie abgeschlossen, sondern flexibel. Sie werden immer wieder neu zur Disposition gestellt und sind für neue (oder alte) Deutungen offen.“"147

Hoffentlich konnte mit der Arbeit gezeigt werden, dass vermeintliche Zäsuren nicht unbedingt als gegeben angenommen werden sollen, bzw. dass diese sich nicht in allen Bereichen des Lebens unbedingt durchsetzen. Besonders in der Fest- und Brauchgestaltung, wo Quellen dazu auffindig gemacht werden können, sollen Veränderungen auf der Mikroebene analysiert und gedeutet werden, um über das Schicksal der in Ungarn Verbliebenen mehr zu erfahren. Es lässt sich eindeutig feststellen, dass Formulierungen wie der Blumenteppich bzw. die Tradition vor und nach der Vertreibung stark generalisierend sind. Denn nicht die Vertreibung als Ereignis änderte die Festgestaltung,

146 Marchut 2014: 12.

147 Kleßmann 2014: o.S. 
Die Vertreibung als Zäsur im religiös-kulturellen Leben...

sondern diese wurde den jeweiligen Gegebenheiten angepasst, und zwar nicht auf einmal, sondern Schritt für Schritt. So war 1948 eine Prozession entlang des ursprünglichen Prozessionsweges trotz der Vertreibung und der Abwesenheit des Großteils der Brauchträger und Brauchträgerinnen möglich. Wie unwahrscheinlich sich das auch anhören mag, mit der Vertreibung ging das „alte“ Leben in Budaörs nicht unmittelbar zu Ende. In der Festgestaltung lassen sich vielmehr die Etablierung des neuen sozialistischen Regimes und die Verfolgung der katolischen Kirche, die sich in der Festnahme von Kardinal Mindszenty zuspitze, als mögliche Zäsuren für das Fronleichnamsfest verstehen. Um diese These zu bestätigen, sollten Quellen aus den Jahren nach 1948 zur Forschung herangezogen und ausgewertet werden. Denn, wie aus der vorliegenden Arbeit ersichtlich werden konnte, nicht eine Zäsur ist allgemeingültig und allmächtig für die Analyse verschiedener Entwicklungen eines Zeitraumes und nicht eine Zäsur hat sich in allen Bereichen des Lebens durchgesetzt. Darauf deutet auch Seewann hin, indem er „eine Ungleich-

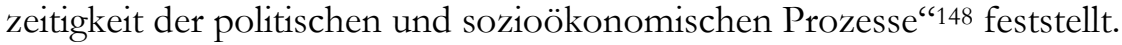

,[Wenn es um Erinnerungsorte als Forschungsparadigma geht, V. M.] sind mit Erinnerungsorten symbolische Repräsentationen gemeint, von denen Forscher und Forscherinnen annehmen, dass sie in bestimmten Gedächtnis- und Identitätsdiskursen eine signifikante Rolle spielen.“149

So kann das Fronleichnamsfest in den Jahren 1944-1948 als Erinnerungsort für den religiös-kirchlichen Widerstand der Budaörser Gläubigen verstanden werden, mit einem demonstrativen Charakter, wodurch es ,zum öffentlichen Bekenntnis katholischer Rechtgläubigkeit [wurde]"150. Dieser Demonstrationscharakter von Fronleichnamsprozessionen ließ sich auch in den Kriegsjahren beobachten. Während dieser ursprünglich in Bewegungen der Gegenreformation in der Abgrenzung der Katholiken von den Reformierten bestand, wurden sie in den Jahren des sich etablierenden sozialistischen Regimes als Demonstration gegen die Idee der sozialistischen Religionsauffassung eingesetzt.

\footnotetext{
148 Seewann 1989: 97.

149 Siebeck 2017: o.S.

150 Fuchs 2006: 35.
} 


\section{Literatur}

ALBERT, Zoltán Máté

2014 Az úgynevezett Kossuth-címer használata szokásjog alapján 19461949 között. Turul (A Magyar Heraldikai és Genealógiai Társaság Közlönye). 1. 20-24.

BEDNÁRIK, János

2014 Virágszőnyeg, egyház, társadalom. In Judit Komor - Katalin Schiller (Hg.): Utak, technikák, hagyományok. 37-57. Budapest: ELTE BTK Történelemtudományi Doktori Iskola

2017 Tradierte Zugehörigkeiten. Generationenübergreifende Aspekte ungarndeutscher Identität in Deutschland. In Réka Szentiványi - Béla Teleky (Hgg.): Brüche - Kontinuitäten - Konstruktionen: Mitteleuropa im 20.

BEER, Mathias Jabrbundert. 211-246. Wien: New Academic Press

2014 Migration und Mythen. Annäherungen. In Beer Mathias (Hg.): Migration und Mythen. Geschichte und Gegenwart - Lokal und Global. Ulm: Süddeutsche Verlagsgesellschaft Ulm

BEER, Mathias (Hg.)

2010 Das Heimatbuch. Geschichte, Methodik, Wirkung. Göttingen: V\&R unipress BERG, Manfred

2011 Der 11. September 2001 - eine historische Zäsur? Zeithistorische Forschungen. 2011/3. 463-474. https://zeithistorische-forschungen.de/32011/4411 - 10.03.2020 https://doi.org/10.14765/zzf.dok-1620

BICKENBACH, Matthias

2013 Die Enden der Alben. Über Ordnung und Unordnung eines Mediums am Beispiel von Rolf Dieter Brinkmanns Schnitte. In Anke Kramer Annegret Pelz (Hg.): Album. Organisationsform narrativer Kobärenz. 107122. Göttingen: Wallstein

BONOMI, Jenő (Eugen)

1933 Az egyházi év Budaörs német község nyelvi és sqokásanyagában (tekintettel Budaörs és környékére). Budapest: Selbstverlag

1964 Mein Weg als Volkskundler. Jahrbuch für ostdeutsche Volkskunde. 8. 273290.

EYBL, Franz M.

2013 Alben der Analphabeten. Religiöse Bücher als Speicher. In Anke Kramer - Annegret Pelz (Hgg.): Album. Organisationsform narrativer Kohärenz. 191-203. Göttingen: Wallstein

FAEHNDRICH, Jutta

2003 Erinnerungskultur und Umgang mit Vertreibung in Heimatbüchern deutschsprachiger Vertriebener. Zeitschrift für Ostmitteleuropa-Forschung. 52. 191-229. 
Die Vertreibung als Zäsur im religiös-kulturellen Leben...

2011 Eine endliche Geschichte. Die Heimatbücher der deutschen Vertriebenen. KölnWeimar-Wien: Böhlau

FILIPSZKY, András - GRÓSZ, András

2009 Budaörs Lexikon. Budaörs története a kezdetektöl napjainkig, sqócikkekeben feldolgozva. Budaörs: Budaörs Város Önkormányzata

FUCHS, Guido

2006 Fronleichnam. Ein Fest in Bewegung. Regensburg: Friedrich Pustet

GERGELY, Jenő

1999 A katolikus egyház, története Magyarországon 1919-1945. Budapest: Pannonica

GRAF, Rüdiger

2011 Zeit und Zeitkonzeptionen in der Zeitgeschichte, Version 2.0. Docupedia-Zeitgeschichte. 20.10.2012.

https://docupedia.de/zg/Zeit und Zeitkonzeptionen Version 2.0 R üdiger_Graf -10.03.2020 https://doi.org/10.14765/zzf.dok.2.266.v2

GRÓSZ, András

2010 Flüchtlinge und Internierte. Budaörs am Ende des Zweiten Weltkriegs. In András Grósz (Hg.): Jogfosztások Budaörsön = Entrechtungen in Budaörs (1944-1948). Budaörs: Bleyer Jakab Helytörténeti Gyüjtemény

GRÓSZ, András (Hg.)

2010 Jogfosztások Budaörsön = Entrechtungen in Budaörs (1944-1948). Budaörs: Bleyer Jakab Helytörténeti Gyűjtemény

HATOS, Pál

2012 Kardinal József Mindszenty (1892-1975) Divergierende Erinnerungen und die Perspektiven der vergleichenden Forschung. In Csaba Szabó (Hg.): József Kardinal Mindszenty in Wien (1971-1975). 9-27. Wien: Institut für Ungarische Geschichtsforschung in Wien u.a.

HIRSCH, Marianne

2013 Der archivale Impuls der Nacherinnerung. In Anke Kramer - Annegret Pelz (Hgg.): Album. Organisationsform narrativer Kobärenz. 125-142. Göttingen: Wallstein

HOLL, Ute

2013 Album, Montage, carte postale. Aspekte medialer Historiografie. Zum Film No pasarán, album souvenir (F 2003) von Henri-François Imbert. In Anke Kramer - Annegret Pelz (Hgg.): Album. Organisationsform narrativer Kohärenz: 89-106. Göttingen: Wallstein KÁLMÁN, Ágnes

2010 Die Budaörser Vertreibung im Spiegel persönlicher Rückerinnerungen. In András Grósz (Hg.): Jogfosq̨ások Budaörsön = Entrechtungen in Budaörs (1944-1948). Budaörs: Bleyer Jakab Helytörténeti Gyűjtemény

KLESSMANN, Christoph

20141945 - welthistorische Zäsur und „Stunde Null“. Docupedia-Zeitgeschichte. 15.10.2010 https://docupedia.de/zg/1945 - 10.03.2020 
KLIMÓ, Árpád von

2012 Kardinal Mindszentys Reisen 1971-1975. Die Reformulierung des Antikommunismus in Westdeutschland und in den USA (in neuen Perspektiven). In Csaba Szabó (Hg.): József Kardinal Mindszenty in Wien (1971-1975). 133-143. Wien: Institut für Ungarische Geschichtsforschung in Wien u.a.

2015 Katholizismus als Verkörperung einer ,aus tausend Wunden blutenden Nation“ (1945-1948). Weltkirchlicher Anspruch und nationale Repräsentation in Kardinal Mindszentys national-katholischer Kampagne. In Johannes Gleixner - Laura Hölzlwimmer - Christian Preusse - Damien Tricoire (Hgg.): Konkurrierende Ordnungen: Verscbränkungen von Religion, Staat und Nation in Ostmitteleuropa vom 16. bis zum 20. Jahrbundert. 257-281. München-Berlin-Lepizig-Washington D.C.: Biblion Media

KOVÁCS, József László

2005 Rögös utakon = Auf steinigen Wegen. Budaörs: Német Nemzetiségi Önkormányzat

KOVÁCSNÉ PAULOVITS, Teréz (Hg.)

2001 Népszokásokés hagyományórzés Budaörsön. Budaörs: Riedl Ferenc Helytörténeti Gyújtemény - Heimatmuseum

KOVÁCSNÉ PAULOVITS, Teréz - KOVÁCS, József László

1999 Úrnapi virágszőnyeg Budaörsön. Honismeret. 3. 82-88.

KRAMER, Anke - PELZ, Annegret (Hgg.)

2013 Album. Organisationsform narrativer Kobärenz: Göttingen: Wallstein

LAKATOS, Andor

2009 A változások évszázada - Fejezetek a Kalocsai Főegyházmegye 20. századi történetéből. In A Kalocsai Érsekség 100 Esztendeje: A KalocsaBácsi Érsekeségtól a Kalocsa-Kecskeméti Fóegyházmegyéig: 1909-2009. Pozsony: Remény Kiadó - Kalocsa: Kalocsa-Kecskeméti Főegyházmegye https://archivum.asztrik.hu/?q=oldal/a-kalocsai-ersekseg-100esztendeje-1909-2009-2009 - 15.03.2020

MARCHUT, Réka

2010 Aus- und Ansiedlungen in Budaörs (1945-1948). In András Grósz (Hg.): Jogfosztások Budaörsön = Entrecbtungen in Budaörs (1944-1948). 169-234. Budaörs: Bleyer Jakab Helytörténeti Gyújtemény

2014 Töréspontok. A Budapest körmyéki németség második világháborút követó felelösségre vonása és annak eló:zményei (1920-1948). Budapest-Budaörs: MTA Társadalomtudományi Kutatóközpont

MARÓTHY-MEIZLER, Károly

1958 Az ismeretlen Mindszenty. Életrajz és korrajæ: Buenos Aires: Editorial Pannonia

MARINKA, Melinda

2012 „Heimatbuch“ - egy sajátos műfaj jellemzőiről és néprajzi hasznosíthatóságáról. Ethnographia. 123. 4. 344-368. 
Die Vertreibung als Zäsur im religiös-kulturellen Leben...

2018 Sathmarschwäbische Heimatbücher als Erinnerungsorte und als ethnografische Quellen. In Melinda Marinka - Róbert Keményfi (Hgg.): Ethnographica et Folk.loristica Carpathica. 20. 69-78.

MOLLER, Sabine

2010 Erinnerung und Gedächtnis. Docupedia-Zeitgeschichte. 12.04.2010 https://docupedia.de/zg/Erinnerung und Gedächtnis - 15.03.2020 https://doi.org/10.14765/zzf.dok.2.323.v1

NOACK, Theresia (Herzog Res/Noack)

2014 Fronleichnam 1944. Unsere Post. Heimatzeitung der Deutschen aus Ungarn. 59. 6. 22 .

PAGENSTECHER, Cord

2009 Private Fotoalben als historische Quelle. Zeithistorische Forschungen/Studies in Contemporary History (Online-Ausgabe). Vol. 6. 3. 449-463. https://zeithistorische-forschungen.de/3-2009/4629 - 14. 03. 2020

PELZ, Annegret

2013 Vom Bibliotheks- zum Albenphänomen. In Anke Kramer - Annegret Pelz (Hgg.): Album. Organisationsform narrativer Kohären₹. 40-58. Göttingen: Wallstein

RETTERATH, Hans-Werner

2011 Die vertriebenen Budaörser und ihre Fronleichnamsprozession. Eine Brauchtranslozierung und ihre Wirkungen. In Michael Prosser-Schell (Hg.): Szenische Gestaltungen christlicher Feste. Beiträge aus dem Karpatenbecken und aus Deutschland. 79-111. Münster-New York-München-Berlin: Waxmann

RIEDL, Franz

1965 Budaörs, Perle des Ofner Berglandes. Freilassing: Pannonia

SABROW, Martin

2014 Zäsuren in der Zeitgeschichte. Docupedia-Zeitgeschichte. 03.06.2013 https://docupedia.de/zg/Zaesuren - 15.03.2020 https://doi.org/10.14765/zzf.dok.2.246.v1

SEEWANN, Gerhard

1989 Das Deutschtum in Ungarn seit 1945. In Georg Brunner (Hg.): Die Deutschen in Ungarn. 97-107. München: Südosteuropa-Gesellschaft

SIEBECK, Cornelia

2017 Erinnerungsorte, Lieux de Mémoire. Docupedia-Zeitgeschichte. 02.03.2017 https://docupedia.de/zg/Siebeck erinnerungsorte v1 de 2017 - 17.03.2020 https://doi.org/10.14765/zzf.dok.2.784.v1

STEINHAUSER, Klára

2002 A régi Budaörs = Das alte Budaörs. Budaörs: Budaörs Város Önkormányzata

2007 Régi budaörsi családok II. = Alte Budaörser Familien II. Budaörs: Budaörsi Német Nemzetiségi Önkormányzat

2010 Vertreibung und Neubeginn aufgrund von Erinnerungen der Budaörser. Splitter. In András Grósz (Hg.): Jogfosztások Budaörsön = Entrech- 
tungen in Budaörs (1944-1948). 169-234. Budaörs: Bleyer Jakab Helytörténeti Gyüjtemény

SCHNABEL, Werner Wilhelm

2013 Das Album Amicorum. Ein gemischtmediales Sammelmedium und einige seiner Variationsformen. In Anke Kramer - Annegret Pelz (Hgg.): Album. Organisationsform narrativer Kohärenæ. 213-239. Göttingen: Wallstein

SCHWARTZ, Elmar von

1930 Die Fronleichnamsfeier in den Ofner Bergen (Ungarn.) Zeitschrift für Volkskunde. 40 (1931). N.F. 2 45-49.

SZABÓ, Csaba (Hg.)

2012 József Kardinal Mindszenty in Wien (1971-1975). Wien: Institut für Ungarische Geschichtsforschung in Wien u.a.

SZABÓ B., Károly

2003 Bonomi, Eugen. In Christoph König (Hg.): Internationales Germanistenlexikon 1800-1950. Bd. 1. 232-233. Berlin-New York: De Gruyter

TIPPNER, Anja

2013 Leben in Bildern. Zum Verhältnis von Album und Bildbiographie am Beispiel Vladimir Nabokovs. In Kramer, Anke - Pelz, Annegret (Hgg.): Album. Organisationsform narrativer Kohärenz. 319-334. Göttingen: Wallstein

TÓTH, Ágnes

2010 Wo sind noch Lücken? Vertreibung der Ungarndeutschen in der heimischen Geschichtsschreibung: thematische weiße Flecken, methodische Mängel. In András Grósz (Hg.): Jogfosztások Budaörsön = Entrechtungen in Budaörs (1944-1948). 169-234. Budaörs: Bleyer Jakab Helytörténeti Gyüjtemény

2020 Németek Magyarországon 1950-1970. Budapest: Argumentum

VEREBÉLYI, Kincső

1998 Blumenteppiche in Ungarn an Fronleichnam. In Bimmer C., Andreas (Hg.): Hessische Blätter für Volks- und Kulturforschung. 191-188. Bd. 34. Marburg: Jonas

WITTINGHOFF, Tamás (Hg.)

1999 Mélyek a gyökereke = Die Wurzeln wachsen tief. Budaörs: Budaörs Város Önkormányzat Polgármesteri Hivatal 
Die Vertreibung als Zäsur im religiös-kulturellen Leben...

Archivquellen

BRKEI Sc.: Scholaria im Archiv der Römisch-Katholischen Pfarrgemeinde Budaörs = Budaörsi Római Katolikus Egyházközség Irattára

PL: Erzbischöfliches Archiv Esztergom = Prímási Levéltár Esztergom

Album: Fotos Nr. 3895-3939.

PL 4455/1948.

PL 5951/1947.

PL 981/1946.

PL 2935/1945.

\section{Internetquellen}

o.A.

o.J. Fotoalben in Ausstellungen und Forschung. In o.A.: Das Fotoalbum. Seine Geschichte und seine Erforschung. https://www.arthistoricum.net/themen/va/geteilteerinnerungen/das-fotoalbum-seine-geschichte-und-seine-

o.A. erforschung/fotoalben-in-ausstellungen-und-forschung/ - 23.03.2020

o.J. $\quad$ FOTO | ALBUM. Private und anonyme Fotografie aus der Sammlung des Werkbundarchiv - Museum der Dinge.

https://www.museumderdinge.de/ausstellungen/foto-album

$-23.03 .2020$

o.A.

o.J. $\quad$ Fremde im Visier - Fotoalben aus dem Zweiten Weltkrieg.

http://www.fremde-im-visier.de/forschungsprojekt.html - 19.03.2020

o.A.

o.J. Mária-év. In Magyar Katolikus Lexikon

http://lexikon.katolikus.hu/M/M\%C3\%A1ria-\% $\% 3 \%$ A9v.html

$-14.03 .2020$

o.A.

o.J. Prohászka Ottokár. In Magyar Katolikus Lexikon

http://lexikon.katolikus.hu/P/Proh\%C3\%A1szka.html - 14.03.2020 


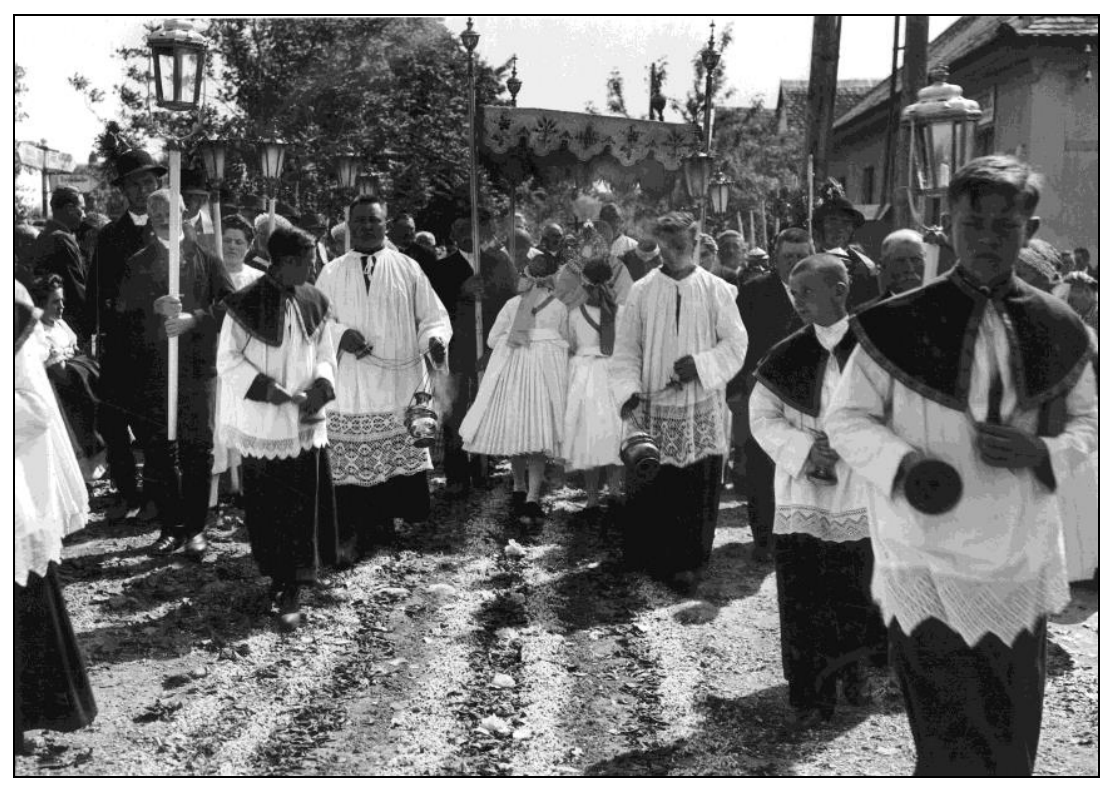

Fronleichnam im Jahr 1943, eine Aufnabme des schweizer

Diplomaten Carl Lutz.

Quelle: Fortepan / Archiv für Zeitgeschichte ETH Zürich / Agnes Hirschi 